\title{
Evaluation of the bioactivities of water-soluble extracts from twelve deep-sea jellyfish species
}

\author{
Takenori Kawabata $\cdot$ Dhugal J. Lindsay $\cdot$ Minoru Kitamura $\cdot$ \\ Satoshi Konishi · Jun Nishikawa $\cdot$ Shuhei Nishida • \\ Michiya Kamio $\cdot$ Hiroshi Nagai
}

Received: 27 October 2012/ Accepted: 27 February 2013/Published online: 10 April 2013

(C) The Author(s) 2013. This article is published with open access at Springerlink.com

\begin{abstract}
Many polypeptides isolated from shallow water cnidarian species have been utilized as valuable biochemical tools in both basic and applied biological sciences. Deepwater cnidarian species might be another potential resource for novel biochemical tools. However, because of limited access to cnidarian samples from deep-sea environments, bioactive polypeptides have never before been reported from this group. In this study, we collected twelve deep-sea jellyfish species (nine hydrozoans and three scyphozoans) using a plankton net that was specially designed for collecting deep-sea organisms, and prepared water-soluble extracts, presumably containing polypeptides, of these jellyfishes. The extracts were subjected to cytotoxicity, hemolytic activity, and crustacean lethal toxicity tests. In the cytotoxicity test, six out of the nine tested hydrozoan species showed activity. In the hemolytic activity test, only three hydrozoans showed activity and none of the scyphozoan jellyfishes showed activity. In the crustacean lethality test, two hydrozoan jellyfishes and all three of the tested scyphozoan jellyfishes showed lethal activity. These results revealed a high incidence of watersoluble bioactive substances occurring in these deepsea jellyfishes. Furthermore, all the heat-treated and the
\end{abstract}

T. Kawabata $\cdot$ M. Kamio $\cdot$ H. Nagai $(\bowtie)$

Tokyo University of Marine Science and Technology,

4-5-7 Konan, Minato-ku, Tokyo 108-8477, Japan

e-mail: nagai@kaiyodai.ac.jp

D. J. Lindsay $\cdot$ M. Kitamura $\cdot$ S. Konishi

Japan Agency for Marine-Earth Science and Technology

(JAMSTEC), Yokosuka, Kanagawa 237-0061, Japan

J. Nishikawa $\cdot$ S. Nishida

Atmosphere and Ocean Research Institute, University of Tokyo,

Kashiwa, Chiba 277-8564, Japan methanol-treated crude jellyfish extracts lost their bioactivities. Thus, it is likely that the bioactive compounds in the water-soluble extracts were unstable polypeptides (proteins). This is the first published report on bioactivities in extracts from deep-sea jellyfishes.

Keywords Jellyfish $\cdot$ Cnidarian $\cdot$ Deep-sea $\cdot$ Bioactivity . Natural product $\cdot$ Toxin $\cdot$ Bioresource

\section{Introduction}

Polypeptides produced by cnidarians can have unique structures and bioactivities. For example, green fluorescent protein (GFP) from the jellyfish Aequorea victoria [1] is an important marker used for identifying gene expression in cell and molecular biology, and some other fluorescent proteins have also been obtained from other cnidarians $[2,3]$. A glycoprotein mucin from the jellyfish Nemopilema nomurai [4] is a potential drug target for osteoarthritis (the most common joint disease) [5]. Hydrolyzed collagen from jellyfishes exhibits desirable pharmacological effects such as angiotensin-I-converting enzyme-inhibitory activity [6] and antihypertensive effects [7]. Jellyfish collagen itself has been reported to have immunostimulatory activity [8]. Furthermore, all cnidarians have venomous polypeptides in their nematocysts, which are stinging organelles [9] used in prey capture. Certain unique polypeptide toxins from sea anemones specifically inhibit some voltage-gated ion channels, and are therefore utilized as valuable biochemical tools in physiological and pharmacological studies [10]. In these previous studies, the cnidarian samples were obtained exclusively from coastal or shallow waters.

Deep-sea cnidarians live under the environmental conditions of high pressure, low water temperature with low 
temporal/spatial variability, and low prey concentrations, so their biochemical metabolism may differ to that of shallow-water cnidarians. As an example, it is generally known that deeper-living fish and crustaceans have higher wax ester contents than those that live near the surface. It has been suggested that these wax esters might have a specific buoyancy function in addition to their known use for energy storage [11, 12]. Unique enzymes have also been found in deep-sea crustaceans. For example, a cellulase from the amphipod Hirondella gigas possesses activity that increases under high hydrostatic pressures of $100 \mathrm{MPa}$ at $2{ }^{\circ} \mathrm{C}$. This enzyme is capable of digesting sunken wooden debris and might be useful for the production of bio-ethanol from raw materials [13]. Thermostable $\beta$-agarase has been isolated from a heat-resistant microorganism from a deep-sea mud sample [14]. This commercially available agarase exhibits thermal resistance and high agarolytic activity. The biomolecules of deep-sea jellyfishes are also intriguing research targets. However, deepwater cnidarian species remain an unexplored resource because the collection of jellyfishes from the deep sea is difficult. In the present study, we collected deep-sea jellyfishes inhabiting the mesopelagic zone (depth of 200-1,000 m) in Sagami Bay between 2004 and 2009 using plankton nets that were specially designed for collecting mesopelagic organisms. Water-soluble extracts obtained from these deep-sea jellyfishes were subjected to (1) cytotoxicity, (2) hemolytic activity and (3) crustacean lethal toxicity tests. The crude extract preparation methods and bioactivity tests adopted in this study have been routinely used in our laboratory for discovering novel bioactive polypeptides from shallow-water cnidarians [15-19].

The final goal of this research is to find useful polypeptides, such as molecular probes for biochemical studies and drug applications. In this article, bioactivity screening results for the water-soluble extracts from deep-sea jellyfishes are presented.

\section{Materials and methods}

\section{Jellyfish collection}

Deep-sea jellyfishes were collected during nine research cruises between 2004 and 2009 in the mesopelagic zone (depth of 200-1,000 m) in Sagami Bay (from lat. $34^{\circ} 50^{\prime} \mathrm{N}$ to $35^{\circ} 10^{\prime} \mathrm{N}$ and from long. $139^{\circ} 20^{\prime} \mathrm{E}$ to $139^{\circ} 30^{\prime} \mathrm{E}$ ) using two large plankton net systems, the Intelligent Operative Net Sampling System (IONESS) [20] and the Isaacs-Kidd midwater trawl (IKMT) [21]. The former net system, IONESS, is a rectangular frame trawl with nine nets; the area of the net mouth is $1.5 \mathrm{~m}^{2}$ when the net frame is towed at a $45^{\circ}$ angle, and the mesh pore size is $0.33 \mathrm{~mm}$. Researchers can open and close the nets at discrete depths and can monitor net status in real time. The latter net, the IKMT, is a large pelagic trawl with a depressor width of $3 \mathrm{~m}$ and a mouth area of about $7-8 \mathrm{~m}^{2}$. Collected samples were identified by one of the authors (D.J.L.) into 12 species. Out of the 12 jellyfish species samples, nine species were hydromedusans (Colobonema sericeum, Crossota rufobrunnea, Halicreas minimum, Pandea rubra, Pantachogon haeckeli, Aeginura grimaldii, Aegina citrea, Arctapodema sp., Solmissus incisa) and three species were scyphomedusans (Atolla vanhoeffeni, Atolla wyvillei, Periphylla periphylla) (Fig. 1). Samples were immediately frozen after collection in a deepfreezer at $-80{ }^{\circ} \mathrm{C}$ and stored in our laboratory at $-30{ }^{\circ} \mathrm{C}$.

Preparation of the jellyfish extracts

Frozen samples of each species were weighed. The samples were crushed with $10 \mathrm{mM}$ PBS, $\mathrm{pH} 7.0$, using a spatula in the cold room at $4{ }^{\circ} \mathrm{C}$ and were centrifuged at $15,000 \mathrm{~g}$ for $20 \mathrm{~min}$ at $2{ }^{\circ} \mathrm{C}$. The supernatant was filtered through a membrane filter (cellulose acetate $0.45 \mu \mathrm{m}$, ADVANTEC, Tokyo, Japan) to obtain the crude extract. This crude water-soluble extract was immediately applied to the bioactivity test after preparation.

Preparation of the heat-treated jellyfish extracts and the methanol-treated jellyfish extracts

The crude extracts of jellyfishes, prepared according to the above methods, were treated with heating and with methanol. These treatments were to give us information about the nature of the active compounds in each crude extract. Aliquots of the crude water-soluble extracts were heated in tightly closed plastic tubes for $10 \mathrm{~min}$ at $95{ }^{\circ} \mathrm{C}$ and stored on crushed ice until they were tested for bioactivity. To $50 \mu \mathrm{l}$ of each crude extract, $450 \mu \mathrm{l}$ of methanol was added and then kept for $4 \mathrm{~h}$ at $4{ }^{\circ} \mathrm{C}$. The mixture was applied to a centrifugal evaporator (VEC310, Iwaki, Japan) until the methanol was completely removed. After evaporation, distilled water was added to the tube to bring the total amount of liquid to $50 \mu \mathrm{l}$. Such samples were tested for bioactivity as methanol-treated jellyfish extracts.

\section{Cytotoxicity test}

Mouse leukemia L1210 cells (obtained from the Cell Resource Center for Biomedical Research, Tohoku University, Japan) were cultured in RPMI-1640 medium (Invitrogen, Carlsbad, CA, USA) supplemented with $10 \%$ heat-inactivated fetal bovine serum (Invitrogen), $100 \mathrm{mg} / \mathrm{l}$ streptomycin, $100 \mathrm{U} / \mathrm{ml}$ penicillin, and $0.3 \mathrm{mg} / \mathrm{ml}$ glutamic acid at $37{ }^{\circ} \mathrm{C}$ in a humidified $5 \% \mathrm{CO}_{2}$ atmosphere. After a 

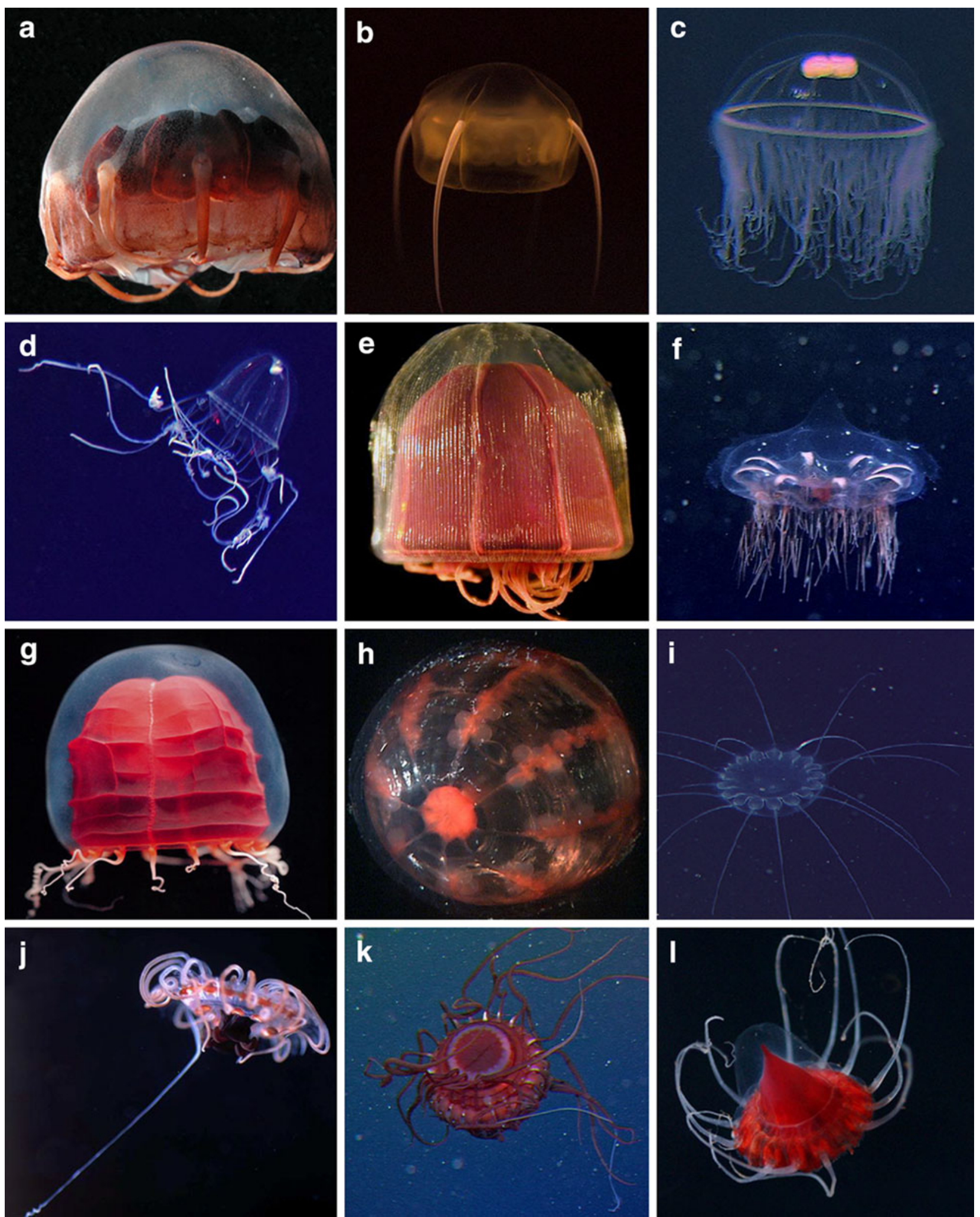

Fig. 1 Photographs of the studied deep-sea jellyfishes. a Aeginura grimaldii, b Aegina citrea, c Arctapodema sp., d Colobonema sericeum, e Crossota rufobrunnea, f Halicreas minimum, g Pandea rubra, $\mathbf{h}$ Pantachogon haeckeli, i Solmissus incisa, $\mathbf{j}$ Atolla vanhoeffeni, k Atolla wyvillei, l Periphylla periphlla. Photography by Drs. Dhugal J. Lindsay (a, g, h, l), Hiroshi Miyake (b), Minoru Kitamura

(e), and James C. Hunt (j). The other photographs were recorded by the hyper-dolphin (remotely operated vehicle) of JAMSTEC. All photographed animals were observed and/or caught in Japanese waters and were identified by DJL. The photographed animals are not the same animals upon which the bioactivity assays were done, although they were identified by the same taxonomist 
Table 1 Cytotoxicity, hemolytic activity, and crustacean lethality tests of the water-soluble extracts from deep-sea jellyfishes

\begin{tabular}{|c|c|c|c|c|c|c|}
\hline Jellyfish species & $\begin{array}{l}\text { Specimen } \\
\text { number }\end{array}$ & $\begin{array}{l}\text { Wet } \\
\text { weight (g) }\end{array}$ & $\begin{array}{l}\text { Crude } \\
\text { extract }(\mathrm{ml})\end{array}$ & $\begin{array}{l}\text { Cytotoxicity } \\
\text { test } \\
\mathrm{IC}_{50}(\mathrm{mg} / \mathrm{ml})\end{array}$ & $\begin{array}{l}\text { Hemolytic activity } \\
\text { test } \\
\mathrm{ED}_{50}(\mathrm{mg} / \mathrm{ml})\end{array}$ & $\begin{array}{l}\text { Crustacean } \\
\text { lethality test } \\
\mathrm{LD}_{50}(\mathrm{mg} / \mathrm{g})\end{array}$ \\
\hline \multicolumn{7}{|l|}{ Hydrozoa } \\
\hline \multicolumn{7}{|l|}{ Anthomedusae } \\
\hline Pandea rubra & 2 & 3.0 & 2.6 & ND & ND & ND \\
\hline \multicolumn{7}{|l|}{ Trachymedusae } \\
\hline Arctapodema sp. & 5 & 2.1 & 1.5 & 190 & 110 & ND \\
\hline Colobonema sericeum & 2 & 7.3 & 6.0 & 420 & 190 & ND \\
\hline Crossota rufobrunnea & 5 & 1.6 & 1.5 & ND & 100 & ND \\
\hline Halicreas minimum & 2 & 3.7 & 3.2 & 750 & ND & ND \\
\hline Pantachogon haeckeli & 5 & 1.7 & 1.3 & 160 & ND & 5.6 \\
\hline \multicolumn{7}{|l|}{ Narcomedusae } \\
\hline Aeginura grimaldii & 2 & 1.7 & 1.2 & 170 & ND & ND \\
\hline Aegina citrea & 2 & 2.6 & 2.8 & 100 & ND & ND \\
\hline Solmissus incisa & 2 & 5.2 & 4.2 & ND & ND & 11.0 \\
\hline \multicolumn{7}{|l|}{ Scyphozoa } \\
\hline \multicolumn{7}{|l|}{ Coronatae } \\
\hline Atolla vanhoeffeni & 2 & 5.1 & 4.5 & 740 & ND & 3.2 \\
\hline Atolla wyvillei & 2 & 7.0 & 6.5 & ND & ND & 2.0 \\
\hline Periphylla periphylla & 2 & 2.0 & 1.5 & ND & ND & 6.5 \\
\hline
\end{tabular}

Lethal dose $50 \%$ (LD50) was calculated according to the Litchfield and Wilcoxon method [22], monitoring for lethality every $30 \mathrm{~min}$ for $4 \mathrm{~h}$. IC50 the concentration $(\mu \mathrm{g} / \mathrm{ml})$ inducing $50 \%$ loss of cell viability in mouse leukemia L1210 cultured cells $\left(5 \times 10^{5}\right.$ cell $\left./ \mathrm{ml}\right), E D 50$ effective dose for $50 \%$ hemolysis of a $0.8 \%$ suspension of sheep red blood cells, $L D 50$ diluted crude extract (5 $\mu 1)$ was injected into the abdominal cavity of the shrimp Palaemon paucidens $(N=3-5), m g$ the wet weight of the corresponding jellyfish sample, $m l$ the volume of the final mixture volume, $g$ the wet weight of the corresponding tested shrimp Palaemon paucidens, $N D$ not detected at concentration tested

cultivation period of 3 days, cultured cells $\left(5 \times 10^{5}\right.$ cell $/ \mathrm{ml}$, $100 \mu \mathrm{l})$ were seeded onto 96-well culture plates, and $15 \mu \mathrm{l}$ of each crude extract diluted with $10 \mathrm{mM}$ phosphate buffered saline (PBS) at pH 7.0, was added to each well. Each sample was prepared in triplicate. After $18 \mathrm{~h}$ incubation at $37{ }^{\circ} \mathrm{C}$ in a $\mathrm{CO}_{2}$ incubator, the wells were incubated for $6 \mathrm{~h}$ with $50 \mu$ of 2,3-bis (2-methoxy-4-nitro-5-sulfophenyl)2H-tetrazolium-5-carboxanilide inner sodium salt (XTT, Sigma, St. Louis, MO, USA) working solution. XTT working solution was prepared as a mixture of $5.5 \mathrm{ml}$ of XTT in RPMI-1640 medium $(1 \mathrm{mg} / \mathrm{ml})$ and $170 \mu \mathrm{l}$ of phenazine methosulfate (Sigma, USA) in RPMI-1640 medium $(38 \mu \mathrm{g} / \mathrm{ml})$. Colorimetric changes of XTT in the redox reaction to investigate cell viability were determined by measuring absorbance (A) in a microtiter plate reader (Model 550, Biorad, Hercules, CA) at dual wavelengths of 450 and $655 \mathrm{~nm}$. Data were calculated as percentage of inhibition according to the following formula.

Inhibition $(\%)=\left\{1-\left(A_{450,655}\right.\right.$ sample - blank

$$
\left./ A_{450,655} \text { control - blank) }\right\} \times 100 \text {. }
$$

$A_{450,655}$ sample and $A_{450,655}$ control are the absorbances for the cells with sample extract and the control cells, respectively, and "blank" is the absorbance of the blank control. The $\mathrm{IC}_{50}$ value was defined as the concentration (wet weight of tissue per cultured cells) where a $50 \%$ loss of cell viability was observed in the cultured cells.

Hemolytic activity test

Fifty microliters of each crude extract in serial dilution with $10 \mathrm{mM}$ PBS, $\mathrm{pH} 7.0$, was incubated in micro tubes with a $400 \mu \mathrm{l}(0.8 \%)$ suspension of sheep red blood cells (Nippon Biotest Laboratories Inc., Tokyo, Japan) in the PBS at $37{ }^{\circ} \mathrm{C}$ for $2 \mathrm{~h}$. Cell suspensions were centrifuged at $2,000 \times g$ for $10 \mathrm{~min}$ and $100 \mu \mathrm{l}$ of supernatant was transferred to a 96-well flat-bottom microtiter plate. Each sample was prepared in triplicate. The absorbance $(A)$ was measured at $570 \mathrm{~nm}$ using a microtiter plate reader (Model 550, Biorad, Hercules, CA). Effective dose $50 \%$ $\left(\mathrm{ED}_{50}\right)$ hemolysis was calculated using the following formula.

Hemolysis $(\%)=\left(A_{\text {sample }}-A_{\text {blank }}\right) /\left(A_{\text {saponin }}-A_{\text {blank }}\right) \times 100$.

PBS was used as a negative control, $0.2 \%$ saponin as a positive control. The concentration of $\mathrm{ED}_{50}$ was defined as wet weight of tissue per $0.8 \%$ suspension of sheep red blood cells. 
Crustacean lethality test

The shrimp Palaemon paucidens was used for the crustacean lethality test. Each crude extract $(5 \mu \mathrm{l})$ in two-fold serial dilutions with $10 \mathrm{mM}$ PBS ( $\mathrm{pH} 7.0$ ) was injected into the abdominal cavity of the shrimp $(n=3-5)$. They were then monitored every $30 \mathrm{~min}$ for $4 \mathrm{~h}$. Lethal dose $50 \%\left(\mathrm{LD}_{50}\right)$ was calculated by the Litchfield and Wilcoxon method [22]. PBS in $0.5 \mathrm{M} \mathrm{NaCl}, \mathrm{pH} 7.0$, was used as a reference. $\mathrm{LD}_{50}$ was defined as wet weight of tissue per unit weight of crustacean.

\section{SDS-PAGE}

Diluted crude extracts from Atolla vanhoeffeni and Atolla wyvillei with the same volume of $10 \mathrm{mM}$ PBS (pH 7.0) were dissolved in $0.01 \mathrm{M}$ Tris- $\mathrm{HCl}$ buffer ( $\mathrm{pH}$ 6.8), containing $2 \%$ sodium dodecyl-sulfate (SDS), $10 \%$ glycerol, $2.5 \%$ dithiothreitol and $0.02 \%$ bromophenol blue, and were heated at $95{ }^{\circ} \mathrm{C}$ for $5 \mathrm{~min}$. Aliquots of the $10 \mu \mathrm{l}$ and low molecular weight marker (GE Healthcare, Buckinghamshire, UK) were applied to the lanes of a polyacrylamide gel (12.5\% acrylamide). Sodium dodecyl-sulfate polyacrylamide gel electrophoresis (SDS-PAGE) was performed according to the method of Laemmli [23] with the constant current $25 \mathrm{~mA}$ and voltage limited to $300 \mathrm{~V}$ for 60 min with a power supply (AE-8155, Atto, Japan). After electrophoresis, polypeptide bands were visualized using a

Fig. 2 Silver-stained SDS-PAGE $(12.5 \%$ acrylamide) of the jellyfish extracts. a The polypeptide bands from the crude extract of Atolla wyvillei. b The polypeptide bands from the crude extract of A. vanhoeffeni

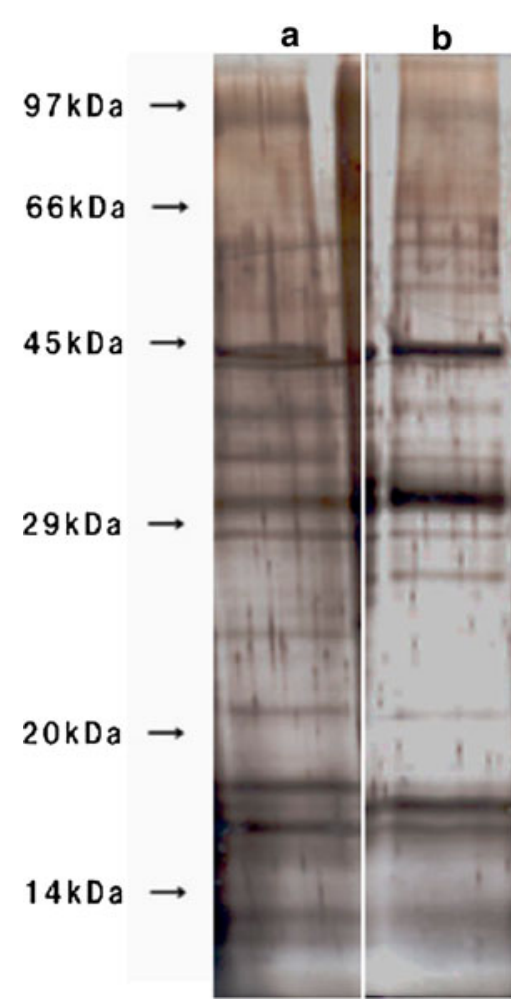

silver stain kit (Kanto-Kagaku, Japan). The protein concentration in the crude extracts was determined using a Pierce ${ }^{\circledR}$ bicinchoninic acid (BCA) Protein Assay Kit (Thermo scientific, Rockford, IL, USA) with bovine serum albumin (Sigma, USA) as the protein standard.

\section{Results}

Preparation of the water-soluble crude extracts from deep-sea jellyfish

Of the 12 sampled species, the amount of available material for Arctapodema sp. and Pantachogon haeckeli was especially low and five individuals of each of these species were utilized for preparation of the water-soluble crude extracts. The sample wet weights utilized for preparation of crude extract ranged from 1.7 to $7.3 \mathrm{~g}$. The volumes of the crude extract obtained ranged from 1.2 to $6.5 \mathrm{ml}$ (Table 1).

\section{Cytotoxicity test}

When the ratio of inhibition of the growth of L1210 mouse leukemia cells by the original crude extract was greater than $50 \%$, the tested crude extract of deep-sea jellyfish was defined as an active sample and its $\mathrm{IC}_{50}$ value was shown in Table 1. Six hydrozoan species, Aeginura grimaldii, Aegina citrea, Arctapodema sp., Colobonema sericeum, Halicreas minimum and Pantachogon haeckeli, and one scyphozoan, Atolla vanhoeffeni, showed apparent cytotoxic activity. Extract from the hydrozoan jellyfish Aegina citrea had the most potent cytotoxicity among all of the tested samples (Table 1). Neither the heat-treated nor the methanol-treated jellyfish extracts of any of the species showed cytotoxic activity.

\section{Hemolytic activity test}

Extracts from only three hydrozoan jellyfishes, Arctapodema sp., Colobonema sericeum and Crossota rufobrun$n e a$, exhibited hemolytic activity (Table 1). None of the scyphozoan jellyfish extracts exhibited hemolytic activity. The extract of $C$. rufobrunnea showed the most potent hemolytic activity $\left(\mathrm{ED}_{50}\right.$ value, $\left.100 \mathrm{mg} / \mathrm{ml}\right)$. Neither the heat-treated nor the methanol-treated jellyfish extracts of any of the species showed hemolytic activity.

\section{Crustacean lethality test}

Lethal activity was detected in the extracts of two hydrozoan jellyfishes Pantachogon haeckeli and Solmissus incisa 
(Table 1). The crude extracts of all of the three tested scyphozoan jellyfishes (Atolla vanhoeffeni, Atolla wyvillei, and Periphylla periphylla) exhibited lethal activity (Table 1). Among these five jellyfishes, the extract from Atolla wyvillei had the most potent lethal activity $(2.0 \mathrm{mg} / \mathrm{g}$, Table 1$) . \mathrm{In}$ addition, paralytic activity on the tested shrimp was observed only for the $S$. incisa crude extract. Neither the heat-treated nor the methanol-treated jellyfish extracts of any of the species showed crustacean lethality activity.

\section{SDS-PAGE}

Results in the SDS-PAGE of the crude extracts from Atolla vanhoeffeni and Atolla wyvillei are shown in Fig. 2. It was revealed that both crude extracts contain numerous polypeptides. The protein concentration of crude extract from A. vanhoeffeni (2.2 mg protein $/ \mathrm{ml}$ ) and $A$. wyvillei (1.3 $\mathrm{mg}$ protein $/ \mathrm{ml}$ ) was quantified by the BCA methods.

\section{Discussion}

In this study, the active compound extractions were done with buffer because our final research targets were polypeptides in the water-soluble polar fraction. So far, most of the bioactive compounds obtained from marine organisms have been extracted with organic solvents such as methanol and acetone, because traditional natural product studies on marine animals have been mainly carried out on non- or less-polar compounds rather than on water-soluble highly polar compounds such as polypeptides [24, 25]. During this study, in spite of keeping the crude extracts in the refrigerator or freezer, all of the extracts exhibited large decreases in activity within a few days. It has also been reported that most of the jellyfish polypeptide toxins studied to date are very unstable during the purification process [26]. Furthermore, all the heat-treated and the methanol-treated crude jellyfish extracts lost their cytotoxic, hemolytic, and lethal activities. From these results, it is inferred that the bioactive compounds in the water-soluble extracts in this study were unstable polypeptides (proteins). Therefore, both extracts from Atolla vanhoeffeni (11 $\mu \mathrm{g}$ total polypeptide per lane) and Atolla wyvillei $(7 \mu \mathrm{g}$ total polypeptide per lane) were checked with SDS-PAGE, because these extracts showed potent crustacean lethal activities. However, it is impossible to speculate as to which polypeptide band(s) corresponds to the crustacean lethal compound(s), assuming that the active compound(s) is or are polypeptide(s). To identify the active compound(s), it is necessary to purify the bioactive substance(s) from the deep-sea jellyfishes while being guided by bioactivity tests such as those used in this study.
The cytotoxicity tests revealed that more than $50 \%$ of the tested jellyfish species contain cytotoxic compounds (Table 1). Cytotoxicity tests have been widely used in screening for anticancer agents in pharmaceutical research $[27,28]$. Thus, the deep-sea jellyfish species that showed cytotoxicity might be potential bioresources for future anticancer drugs.

The results of the hemolytic activity tests showed that hemolytically active compounds clearly existed in three of the hydrozoan jellyfish tested (Table 1). The hemolytically active compounds were found in members of the order Trachymedusae. All previously characterized hemolytic water-soluble compounds from shallow water cnidarians have been polypeptides [29]. Hemolytic active compounds are occasionally cytolytic, too. For example, actinoporins (toxic polypeptides from sea anemones) show both hemolytic and cytolytic activities. The mode of action of actinoporins is attributed to the formation of small pores in the cell membrane with oligomerization of three or four actinoporin molecules [30]. Similarly, the extracts of Arctapodema sp. and C. sericeum showed both hemolytic and cytotoxic activities, and thus might have pore-forming cytolytic toxins such as actinoporins. An anticancer effect in a member of the actinoporins has been reported [31]. Thus, the hemolytic compounds from deep-sea jellyfish might have the potential for such a medicinal use.

The crustacean lethality test found toxic activity in two hydrozoan jellyfishes and all three of the tested scyphozoan jellyfishes. All three schypozoan jellyfishes had rather potent lethal toxicity compared with the two hydrozoans (Table 1). Crustacean lethal polypeptide toxins isolated from box jellyfishes such as Carybdea rastoni [26], Carybdea alata [32], and Chiropsalmus quadrigatus [33] belong to a novel polypeptide family designated as the box jellyfish toxin family [16] and it may also be the case that a novel polypeptide toxin family could be present in the three coronate scyphozoan medusae. To date, some pharmaceuticals have been developed from marine natural toxins. For example, an anticancer drug Eribulin ${ }^{\circledR}$ [34] was developed from a cytotoxin halichondorin $\mathrm{B}$ isolated from a sponge [35]. An intractable pain reliever Prialt ${ }^{\circledR}$ was developed from $\omega$-conotoxin MVIIA from the marine Conus snail [36]. Furthermore, Yondelis ${ }^{\circledR}$ for treatment of sarcoma was also discovered as the potent cytotoxin ecteinascidin 743 from a Caribbean tunicate [37]. These results encouraged us to investigate the toxins of marine animals including deep-sea jellyfish.

Many of the deep-sea jellyfishes used in this study had been physically damaged during the collection process by collisions with the mesh of the plankton net. For example, jellyfishes other than the scyphozoan species and the hydrozoan S. incisa had lost most of their tentacles, which 
usually are armed with huge numbers of nematocysts that are responsible for the injection of venom into their prey. Therefore, it is suggested that the crude extracts used in this study are mainly from body tissues that do not contain large numbers of venomous nematocysts. Scyphozoans retain their tentacles during sampling and this may have contributed to the higher toxicity of their venom in our experiment. In this study, we could not investigate the bioactivities specifically associated with tentacle-borne nematocyst venom in deep-sea jellyfishes. However, the crude extracts from the samples definitely showed various bioactivities (Table 1). In previous studies, it has been shown that some cnidarian bioactive polypeptides exist in non-nematocyst tissue rather than in the nematocysts. For example, the polypeptide toxin CrTX-B in the jellyfish Carybdea rastoni did not exist in the nematocysts but rather in the tentacle tissue [26]. A paralytic and cytolytic 27-kDa polypeptide, termed hydralysin, was isolated from the body of the cnidarian green hydra Chlorohydra viridissima rather than from the nematocysts [38]. A novel antimicrobial polypeptide aurelin was isolated from the mesoglea of the jellyfish Aurelia aurita [39]. In this manner, bioactive polypeptides can be found not only in the nematocysts but also in non-nematocyst tissue. In this study, the observed activities of extracts from jellyfishes might be caused by compounds originating from nonnematocyst sources.

In any case, this study showed a high incidence of water-soluble bioactive substances in deep-sea jellyfishes. Eleven out of the twelve tested deep-sea jellyfishes had cytotoxic, hemolytic, or crustacean lethal activities. The results showed that deep-sea jellyfishes might be potential bioresources for searching for new bioactive compounds. The collection of these deep-sea jellyfishes in pristine condition would be invaluable for future research on their bioactive compounds. It is hoped this problem will be resolved by advances in deep-sea research technology. To the best of our knowledge, this study is the first report on the evaluation of bioactivities in deep-sea jellyfish extracts.

\begin{abstract}
Acknowledgments The authors thank the crews of JAMSTEC research vessels and the members of Marine Work Japan Ltd. for their help with sample collection. The authors also thank Dr. R. Kitatani of Tokyo University of Marine Science and Technology (TUMSAT) for assistance in sample collection and Ms. A. Momose of TUMSAT for the crustacean toxicity assay. This work was supported partly by the Naito Foundation and the Astellas Foundation for Research on Medicinal Resources (to H.N.), and by JSPS Grant-in-Aid for Scientific Research Grant Numbers 20510197, 24510294 (to H.N.).
\end{abstract}

Open Access This article is distributed under the terms of the Creative Commons Attribution License which permits any use, distribution, and reproduction in any medium, provided the original author(s) and the source are credited.

\section{References}

1. Shimomura O (1979) Structure of the chromophore of Aequorea green fluorescent protein. FEBS Lett 104:220-222

2. Ip DT, Wong KB, Wan DC (2007) Characterization of novel orange fluorescent protein cloned from cnidarian tube anemone Cerianthus sp. Mar Biotechnol 9:469-478

3. Ikmi A, Gibson MC (2010) Identification and in vivo characterization of NvFP-7R, a developmentally regulated red fluorescent protein of Nematostella vectensis. PLoS One 5:e11807

4. Masuda A, Baba T, Dohmae N, Yamamura M, Wada H, Ushida K (2007) Mucin (Qniumucin), a glycoprotein from jellyfish, and determination of its main chain structure. $\mathrm{J}$ Nat Prod 70:1089-1092

5. Ohta N, Sato M, Ushida K, Kokubo M, Baba T, Taniguchi K, Urai M, Kihira K, Mochida J (2009) Jellyfish mucin may have potential disease-modifying effects on osteoarthritis. BMC Biotechnol 9:1-11

6. Zhuang Y, Sun L, Li B (2010) Production of the angiotensin-Iconverting enzyme (ACE)-inhibitory peptide from hydrolysates of jellyfish (Rhopilema esculentum) collagen. Food Bioprocess Technol 5:1622-1629

7. Zhuang Y, Sun L, Zhang Y, Liu G (2012) Antihypertensive effect of long-term oral administration of jellyfish (Rhopilema esculentum) collagen peptides on renovascular hypertension. Mar Drugs 10:417-426

8. Morishige H, Sugahara T, Nishimoto S, Muranaka A, Ohno F, Shiraishi R, Doi M (2011) Immunostimulatory effects of collagen from jellyfish in vivo. Cytotechnology 63:481-492

9. Tardent P (1995) The cnidarian cnidocyte, a high-tech cellular weaponry. BioEssays 17:351-362

10. Honma T, Shiomi K (2005) Peptide toxins in sea anemones: structural and functional aspects. Mar Biotechnol 8:1-10

11. Nevenzel JC, Rodegker W, Robinson JS, Kayama M (1969) The lipids of some lantern fishes (Myctophidae). Comp Biochem Physiol 31:25-36

12. Morris RJ (1972) The occurrence of wax esters in crustaceans from the North-east Atlantic Ocean. Mar Biol 16:102-107

13. Kobayashi H, Hatada $\mathrm{Y}$, Tsubouchi T, Nagahama T, Takami $\mathrm{H}$ (2012) The hadal amphipod Hirondellea gigas possessing a unique cellulase for digesting wooden debris buried in the deepest seafloor. PLoS ONE 7:e42727

14. Ohta Y, Nogi Y, Miyazaki M, Li Z, Hatada Y, Ito S, Horikoshi K (2004) Enzymatic properties and nucleotide and amino acid sequences of a thermostable beta-agarase from the novel marine isolate, JAMB-A94. Biosci Biotechnol Biochem 68:10731081

15. Nagai H, Oshiro N, Takuwa-Kuroda K, Iwanaga S, Nozaki M, Nakajima T (2002) Novel proteinaceous toxins from the nematocyst venom of the Okinawan sea anemone Phyllodiscus semoni Kwietniewski. Biochem Biophys Res Commun 294:760-763

16. Nagai H (2003) Recent progress in jellyfish toxin study. J Health Sci 49:337-340

17. Satoh H, Oshiro N, Iwanaga S, Namikoshi M, Nagai H (2007) Characterization of PsTX-60B, a new membrane-attack complex/ perforin (MACPF) family toxin, from the venomous sea anemone Phyllodiscus semoni. Toxicon 49:1208-1210

18. Iguchi A, Iwanaga S, Nagai H (2008) Isolation and characterization of a novel protein toxin from fire coral. Biochem Biophys Res Commun 365:107-112

19. Kohno Y, Satoh H, Iguchi A, Nagai H (2009) Characterization of a new hemolytic protein toxin from the sea anemone Anthopleura asiatica. Fish Sci 75:1049-1054

20. Kitamura M, Tanaka Y, Ishimaru T, Mine Y, Noda A, Hamada $H$ (2001) Sagami Bay research report: improvement of multiple 
opening/closing net, IONESS (Intelligent Operative Net Sampling System). J Tokyo Univ Fish 10:149-158 (in Japanese)

21. Isaacs JD, Kidd LW (1953) Isaacs-Kidd midwater trawl final report. SIO Oceanogr Equip Rep 1:1-21

22. Litchfield JT, Wilcoxon F (1949) A simplified method of evaluating dose-effect experiments. J Pharmacol Exp Ther 96:99-113

23. Laemmli UK (1970) Cleavage of structural proteins during the assembly of the head of bacteriophage T4. Nature 277:680-685

24. Quinn RJ (1988) Chemistry of aqueous marine extracts: isolation techniques. In: Scheuer PJ (ed) Bioorganic marine chemistry. Springer, Berlin, pp 1-42

25. Gerwick WH, Moore BS (2012) Lessons from the past and charting the future of marine natural products drug discovery and chemical biology. Chem Biol 19:85-98

26. Nagai H, Takuwa K, Nakao M, Oshiro N, Ito E, Miyake M, Noda M, Nakajima T (2000) Novel proteinaceous toxins from the box jellyfish (sea wasp) Carybdea rastoni. Biochem Biophys Res Commun 28:582-588

27. Mayer AMS, Gustafson KR (2008) Marine pharmacology in 2005-2006: antitumour and cytotoxic compounds. Eur J Cancer 44:2357-2387

28. Harvey AL, Cree IA (2010) High-throughput screening of natural products for cancer therapy. Planta Med 76:1080-1086

29. Nagai H (2012) Marine protein toxins. In: Fattorusso E et al (eds) Handbook of marine natural products. Springer, London, pp 1389-1420

30. Kristan K, Viero G, Serra MD, Macek P, Anderluh G (2009) Molecular mechanism of pore formation by actinoporins. Toxicon 54:1125-1134

31. Fedorov S, Dyshlovoy S, Monastyrnaya M, Shubina L, Leychenko E, Kozlovskaya E, Jin JO, Kwak JY, Bode AM, Dong Z, Stonik V (2010) The anticancer effects of actinoporin RTX-A from the sea anemone Heteractis crispa (=Radianthus macrodactylus). Toxicon 55:811-817

32. Nagai H, Takuwa K, Nakao M, Sakamoto B, Crow LG, Nakajima $\mathrm{T}$ (2000) Isolation and characterization of a novel protein toxin from the Hawaiian box jellyfish (sea wasp) Carybdea alata. Biochem Biophys Res Commun 275:589-594

33. Nagai H, Takuwa-Kuroda K, Nakao M, Oshiro N, Iwanaga S, Nakajima T (2002) A novel protein toxin from the deadly box jellyfish (sea wasp, habu-kurage) Chiropsalmus quadrigatus. Biosci Biotechnol Biochem 66:97-102

34. Towle MJ, Salvato KA, Budrow J et al (2001) In vitro and in vivo anticancer activities of synthetic macrocyclic ketone analogues of halichondrin B. Cancer Res 61:1013-1021

35. Hirata Y, Uemura D (1986) Halichondrins-antitumor polyether macrolides from a marine sponge. Pure Appl Chem 58:701-710

36. Olivera BM, Gray WR, Zeikus R, McIntosh JM, Varga J, Rivier J, de Santos V, Cruz LJ (1985) Peptide neurotoxins from fishhunting cone snails. Science 230:1338-1343

37. Rinehart KL (2000) Antitumor compounds from tunicates. Med Res Rev 20:1-27

38. Zhang M, Fishman Y, Sher D, Zlotkin E (2003) Hydralysin, a novel animal group-selective paralytic and cytolytic protein from a noncnidocystic origin in hydra. Biochemistry 42:8939 8944

39. Ovchinnikova TV, Balandin SV, Aleshina GM, Tagaev AA, Leonova YF, Krasnodembsky ED, Men'shenin AV, Kokryakov VN (2006) Aurelin, a novel antimicrobial peptide from jellyfish Aurelia aurita with structural features of defensins and channelblocking toxins. Biochem Biophys Res Commun 348:514-523 